\title{
Predictors of cognitive impairment and dementia in older people with diabetes
}

\author{
D. G. Bruce - W. A. Davis - G. P. Casey • \\ S. E. Starkstein • R. M. Clarnette • J. K. Foster • \\ O. P. Almeida • T. M. E. Davis
}

Received: 31 July 2007 / Accepted: 24 October 2007 / Published online: 5 December 2007

(C) Springer-Verlag 2007

\begin{abstract}
Aims/hypothesis Diabetes is associated with an increased risk of dementia but the reasons for this association are unclear because there are many potential mechanisms. We explored the relative contribution of diabetes-related variables as predictors of dementia in older individuals with diabetes.

Methods Survivors, aged $\geq 70$ or more, were recruited from an existing observational cohort study $7.6 \pm 1.0$ years after baseline, when they underwent a comprehensive assessment of diabetes, complications and cardiovascular risk
\end{abstract}

D. G. Bruce • W. A. Davis · G. P. Casey • T. M. E. Davis School of Medicine and Pharmacology,

University of Western Australia,

Perth, WA, Australia

\section{S. E. Starkstein • O. P. Almeida}

Western Australian Centre for Health and Ageing,

School of Psychiatry and Neurosciences,

University of Western Australia,

Perth, WA, Australia

R. M. Clarnette

Department of Community and Geriatric Medicine,

Fremantle Hospital,

Fremantle, WA, Australia

\section{J. K. Foster}

Ageing and Alzheimer's Unit, Edith Cowan University,

Sir James McCusker Alzheimer's Disease Research Unit,

Hollywood Private Hospital,

Perth, WA, Australia

D. G. Bruce $(\bowtie)$

School of Medicine and Pharmacology,

University of Western Australia, Fremantle Hospital,

P.O. Box 480, Fremantle, WA 6959, Australia

e-mail: dbruce@cyllene.uwa.edu.au factors. Dementia, probable Alzheimer's disease and cognitive impairment without dementia were diagnosed clinically. Logistic regression modelling determined independent predictors of cognitive diagnoses.

Results Of 302 participants, aged $75.7 \pm 4.6$ years, 28 (9.3\%) had dementia (16 with probable Alzheimer's disease) and 60 (19.9\%) had cognitive impairment without dementia. The major independent longitudinal predictors of dementia were older age (per decade; odds ratio 4.0, 95\% CI 1.59-10.10), diabetes duration (for each 5 years; odds ratio $1.69,95 \%$ CI $1.24-2.32$ ), peripheral arterial disease (odds ratio 5.35, 95\% CI 2.08-13.72) and exercise (which was protective; odds ratio $0.26,95 \%$ CI $0.09-0.73$ ). For Alzheimer's disease, diabetes duration was an independent predictor in addition to age and diastolic blood pressure. The results of the cross-sectional analyses were similar with respect to diabetes duration and peripheral arterial disease. Conclusions/interpretation Peripheral arterial disease is a strong independent risk factor for dementia in diabetes. After adjustment for a wide range of potential risk factors, diabetes duration remains independently associated with dementia and probable Alzheimer's disease, indicating that factors not measured in this study may be important in the pathogenesis of dementia in diabetes.

Keywords Diabetes · Ageing · Dementia ·

Alzheimer's disease $\cdot$ Cerebrovascular disease

$\begin{array}{ll}\text { Abbreviations } \\ \text { AD } & \text { Alzheimer's disease } \\ \text { Apo } & \text { apolipoprotein } \\ \text { CVD } & \text { cerebrovascular disease } \\ \text { FDS } & \text { Fremantle Diabetes Study } \\ \text { MMSE } & \text { Mini-Mental State Examination } \\ \text { PAD } & \text { peripheral arterial disease }\end{array}$




\section{Introduction}

Studies from various populations have consistently shown diabetes to be associated with cognitive deficits and dementia [1-3]. The pathophysiological mechanisms underlying this association are not fully understood, mainly because of the wide range of possible aetiologies. Cerebrovascular disease is likely to be relevant given the significant role it plays in the development of Alzheimer's disease (AD) and vascular dementia [4]. Cardiovascular risk factors and atherosclerosis are also associated with dementia and AD [57] and the combination of diabetes and hypertension confers a high risk of dementia [8, 9]. In addition, non-vascular mechanisms may also contribute to dementia in diabetes [10], including excess formation of advanced glycation endproducts [11] and/or disturbed neuronal insulin signalling that may promote cerebral amyloidosis [12].

In epidemiological studies exploring risk factors for dementia, associations between hyperglycaemia [9, 13] and insulin therapy $[14,15]$ have been reported and longduration diabetes was associated with major cognitive decline [16]. However, these studies have a number of limitations that include adopting methods to diagnose diabetes subject to significant false negative rates $[8,9,15$, 16], incomplete or absent assessments of glycaemic control $[5,8,9,14-16]$ and lack of assessment of microvascular complications [5, 8, 9, 14-16]. In type 2 diabetes, glycaemic control, diabetic complications and the need for insulin treatment are strongly interrelated and in addition they are each related to the duration of diabetes. This means that the study of risk factors for dementia due to diabetes requires that these factors, as well as other suggested cardiovascular and diabetes-related factors, are measured together.

In the present study, we examined risk factors for dementia, cognitive impairment without dementia, dementia and $\mathrm{AD}$ in older diabetic participants drawn from an observational study representative of the Australian diabetic community, in whom comprehensive longitudinal data were available. We distinguished participants with cognitive impairment who were not demented in the sample to increase analytical precision, and we distinguished dementia due to $\mathrm{AD}$, given the controversy about whether diabetes increases the risk of $\mathrm{AD}[5,8]$.

\section{Methods}

Patients We invited surviving participants of the Fremantle Diabetes Study (FDS), who were aged 70 years or more, to participate. The FDS recruited patients between 1993 and 1996, and annual assessments were performed until 2001. Details of recruitment procedures and the characteristics of the sample have been described previously [17, 18].
Between 1 February 2001 and 31 December 2002, 302 of the 587 FDS patients who were alive at the beginning of this period (51.4\%) agreed to participate after being approached by letter and telephone [19]. Of the remaining 285, $66(23.2 \%)$ had died before recruitment, 71 (24.9\%) could not be contacted and $148(51.9 \%)$ declined participation. Of this latter group, $45 \%$ cited health reasons, including dementia, as reasons for non-participation. The Human Rights Committee of Fremantle Hospital approved the study. All participants gave written, informed consent to participation in the study.

Baseline clinical assessment At the baseline assessment between 1993 and 1996, a comprehensive sociodemographic and clinical history was taken, a physical examination was performed and fasting blood and urine samples were collected for biochemical tests, including serum glucose, $\mathrm{HbA}_{1 \mathrm{c}}$, lipoproteins, urinary albumin:creatinine ratio [20] and apolipoprotein E (ApoE) genotype.

Complications were identified using standard definitions. Peripheral sensory neuropathy was defined as a score of $>2 / 8$ on the clinical portion of the Michigan Neuropathy Screening Instrument [21]. Retinopathy was defined as any grade of retinopathy detected by direct and/or indirect ophthalmoscopy in one or both eyes and/or more detailed assessment by an ophthalmologist. Nephropathy was defined as a urinary albumin:creatinine ratio $\geq 3.0 \mathrm{mg} / \mathrm{mmol}$ in an early morning urine sample [22]. Self-reported stroke and transient ischaemic attack were amalgamated with prior hospitalisations for these conditions to define baseline cerebrovascular disease (CVD). CHD was defined if there was a self-reported history of (or hospitalisation for) myocardial infarction, angina, coronary artery bypass grafting, angioplasty, and/or definite myocardial infarction on a Minnesota coded electrocardiograph [20]. The ankle/ brachial index was obtained from brachial and ankle systolic blood pressures using Doppler detection. Peripheral arterial disease (PAD) was defined as an ankle:brachial index $\leq 0.90$ or the presence of a diabetes-related lowerextremity amputation [23]. Depression was assessed with a depression symptom questionnaire previously shown to diagnose depression in participants with type 2 diabetes with $83.3 \%$ sensitivity and $94.5 \%$ specificity [24].

Annual reviews FDS recruits were asked to attend for subsequent annual reviews for a possible 5 years from baseline, during which information was updated. These additional data, combined with data collected, at baseline and at the time of cognitive assessments provided, a mean $\left( \pm \mathrm{SD}\right.$ ) of $7 \pm 2$ values for $\mathrm{HbA}_{1 \mathrm{c}}$ and $\mathrm{BP}$ in the sample.

Cognitive assessment This was conducted in 2001 and 2002. The FDS assessment template was followed with 
some modifications. Incident CVD and CHD were ascertained by self-report supplemented by scrutiny of hospital records. The questionnaire included additional items on severe hypoglycaemia (hospitalisation or unconsciousness), head injury and family history of dementia. The modified Barthel index assessed basic activities of daily living and was supplemented by questions on instrumental activities of daily living (transport, financial affairs, telephone use, control of medication).

A two-step procedure was used for assessment of cognitive function, with initial screening followed by more detailed assessment. The screen utilised sensitive cutoff points to detect early cognitive impairment and was defined by a Mini-Mental State Examination (MMSE) score $<28 / 30$ [25] or a score $\geq 3.1$ on the Informant Questionnaire for Cognitive Decline in the Elderly (IQCODE) [26] or subjective memory loss. The IQCODE is a reliable informant questionnaire that is unaffected by education or language. Research staff with requisite language skills rated non-English versions of the MMSE (Italian in 39 participants, Croatian in four participants and Portuguese in two participants) when necessary.

Participants positive in the screen underwent neurocognitive testing (global cognition, premorbid intelligence, memory, language, visuospatial, executive functions; data not presented) and an assessment by clinicians experienced in the diagnosis of cognitive disorders (D. G. Bruce, R. M. Clarnette, O. P. Almeida). The clinical assessment included an informant whenever possible, a standard neurological history and examination (for CVD) and scrutiny of hospital records for supplementary data. Patients with dementia were offered brain magnetic resonance imaging (MRI), and/ or existing recent clinical brain scan (MRI or computed tomography) data were collected where available. A random sample of participants who screened negative (34 participants, $11.3 \%$ ) underwent the same assessment protocol to check the screening method; none of these participants had cognitive impairment or dementia. Ratings of functional capacity were based on the Clinical Dementia Rating scale [27]. Dementia was diagnosed clinically using Diagnostic and Statistical Manual of Mental Disorders, Fourth Edition (DSM-IV) criteria. Diagnoses of cognitive impairment without dementia were based on the clinical exclusion of dementia and all had a Clinical Dementia Rating scale rating of 0.5 . Dementia subtypes were classified using standard criteria for $\mathrm{AD}$, vascular dementia and dementia with Lewy bodies [28-30]. All cognitive diagnoses were finalised at consensus meetings of the investigators using all available information.

Some participants failed to complete the protocol because of withdrawal or lack of informant $(n=46)$. Of these, 26 underwent clinical or neurocognitive assessments and the remaining 20 were judged to be cognitively normal based on absence of memory complaints, normal MMSE scores $(\geq 27)$ and supplementary data from hospital records. Of 173 participants who screened positive, all except six underwent a clinical assessment. Two clear-cut cases of dementia were diagnosed without clinical assessment based on available data.

Statistics The computer package SPSS for Windows (version 11.5) was used. Data are presented as proportion, mean $\pm \mathrm{SD}$, geometric mean (SD range) or (in the case of variables which did not conform to a normal or log-normal distribution) medians and interquartile range (IQR). Where annual values of variables were available, updated means were calculated.

For multiple comparisons of independent samples, the $\chi^{2}$ test was used for proportions, ANOVA for normally distributed continuous variables, and the Kruskal-Wallis $H$ test for non-normally distributed variables. For two-sample comparisons of proportions we used Fisher's exact test, for normally distributed variables we used Student's $t$ test, and for non-normally distributed variables we used the MannWitney $U$ test. Multiple logistic regression analysis using forward conditional modelling $(p<0.05$ for entry and $>0.10$ for removal) was performed to determine independent associates of cognitive categories. All clinically plausible variables with $p<0.20$ in the respective bivariate analyses were considered for the models.

\section{Results}

Sample characteristics and prevalence of cognitive diagnoses The 302 study participants were aged $76.0 \pm 4.6$ years, $48.3 \%$ were male and nine lived in residential care. The duration of clinical diabetes was 11.2 (IQR 8.5-16.5) years, $99.0 \%$ had type 2 diabetes, $46.4 \%$ had $\mathrm{HbA}_{1 \mathrm{c}}$ levels $\leq 7$ and $36.4 \%$ were obese. The duration of follow-up was $7.6 \pm$ 1.0 years. In comparison with the present sample, the 285 eligible participants who declined participation were older ( $77.4 \pm 6.3$ vs $75.0 \pm 4.6$ years, $p<0.001$ ), had a longer duration of diabetes [11.9 (IQR 8.6-18.1) vs 10.3 (IQR $7.5-15.4)$ years, $p<0.001]$ and were more likely to die during the recruitment period ( 23.8 vs $4.3 \%, p<0.001)$.

Dementia was present in 28 participants $(9.3 \%)$ and cognitive impairment without dementia in 60 (19.9\%). The causes of dementia were probable AD (16 participants), possible $\mathrm{AD}$ with stroke (eight participants), probable vascular dementia (three participants) and probable Lewy body dementia (one participant). Neuroradiological data were available in 17 participants (ten with probable AD).

Cross-sectional associations Table 1 summarises the characteristics of patients classified by cognitive status at the 
Table 1 Cross-sectional associations at the time of cognitive assessment by cognitive categories (cognitive impairment cases are non-demented)

\begin{tabular}{|c|c|c|c|c|}
\hline & $\begin{array}{l}\text { Normal } \\
(n=214)\end{array}$ & $\begin{array}{l}\text { Cognitive impairment } \\
(n=60)\end{array}$ & $\begin{array}{l}\text { Dementia } \\
(n=28)\end{array}$ & $p$ value $^{\mathrm{c}}$ \\
\hline Age at assessment & $75.1 \pm 4.3$ & $76.1 \pm 4.6$ & $79.3 \pm 5.1^{\mathrm{d}}$ & 0.001 \\
\hline Sex $(\%$ male $)$ & 44.4 & 61.7 & 50.0 & 0.053 \\
\hline Type of diabetes ( $\%$ type 2 ) & 99.1 & 98.3 & 100 & 0.75 \\
\hline Duration diabetes (years) $^{\mathrm{a}}$ & $10.8(8.3-15.4)$ & $12.1(8.6-18.1)$ & $13.7(9.6-21.4)^{\mathrm{d}}$ & 0.037 \\
\hline \multicolumn{5}{|l|}{ Ethnicity $(\%)$} \\
\hline Anglo-Celt & 69.6 & 71.7 & 71.4 & 0.94 \\
\hline Southern European & 16.4 & 23.3 & 17.9 & 0.46 \\
\hline Education ( $\%$ >primary school) & 76.9 & 75.0 & 71.4 & 0.80 \\
\hline Not fluent in English (\%) & 13.6 & 13.3 & 17.9 & 0.82 \\
\hline \multicolumn{5}{|l|}{ Diabetic treatment $(\%)$} \\
\hline Diet & 18.2 & 11.7 & 17.9 & 0.48 \\
\hline Oral hypoglycaemic agent & 57.3 & 53.3 & 46.4 & 0.50 \\
\hline Insulin (with or without oral hypoglycaemic agent) & 24.3 & 35.0 & 35.7 & 0.15 \\
\hline Fasting glucose $(\mathrm{mmol} / \mathrm{l})^{\mathrm{a}}$ & $8.0(6.5-9.7)$ & $8.0(6.3-9.9)$ & $8.2(6.6-9.8)$ & 0.96 \\
\hline $\mathrm{HbA}_{1 \mathrm{c}}(\%)^{\mathrm{a}}$ & $7.1(6.5-8.0)$ & $7.2(6.6-8.3)$ & $7.3(6.7-8.3)$ & 0.49 \\
\hline BMI $\left(\mathrm{kg} / \mathrm{m}^{2}\right)$ & $28.6 \pm 4.7$ & $29.5 \pm 4.2$ & $26.6 \pm 4.7$ & 0.050 \\
\hline Overweight/obese waist/hip ratio (\%) & 76.3 & 71.7 & 77.3 & 0.75 \\
\hline Hypoglycaemia, hospitalised (\%) & 3.8 & $14.0^{\mathrm{e}}$ & $16.0^{\mathrm{e}}$ & 0.004 \\
\hline Systolic BP (mmHg) & $151 \pm 24$ & $157 \pm 22$ & $146 \pm 23$ & 0.07 \\
\hline Diastolic BP (mmHg) & $75 \pm 17$ & $77 \pm 15$ & $79 \pm 26$ & 0.45 \\
\hline Mean arterial pressure $(\mathrm{mmHg})$ & $100 \pm 15$ & $104 \pm 14$ & $101 \pm 19$ & 0.32 \\
\hline BP-lowering medication $(\%)$ & 82.3 & 81.0 & 71.4 & 0.39 \\
\hline Cholesterol $(\mathrm{mmol} / \mathrm{l})$ & $4.8 \pm 0.9$ & $4.7 \pm 0.9$ & $4.8 \pm 1.1$ & 0.82 \\
\hline HDL-cholesterol (mmol/1) & $1.3 \pm 1.0$ & $1.2 \pm 0.3$ & $1.3 \pm 0.4$ & 0.61 \\
\hline Serum triacylglycerol $(\mathrm{mmol} / \mathrm{l})^{\mathrm{b}}$ & $1.5(0.3-7.5)$ & $1.4(0.9-2.4)$ & $1.4(0.8-2.5)$ & 0.57 \\
\hline Lipid-lowering medication $(\%)$ & 56.7 & 55.2 & $25.0^{\mathrm{e}}$ & 0.007 \\
\hline Albumin:creatinine ratio $(\mathrm{mg} / \mathrm{mmol})^{\mathrm{b}}$ & $3.5(0.8-16.3)$ & $3.0(0.5-16.0)$ & $8.1(1.7-39.7)$ & 0.047 \\
\hline Nephropathy $(\%)$ & 51.0 & 41.5 & 70.0 & 0.09 \\
\hline Neuropathy $(\%)$ & 30.0 & 38.3 & 39.3 & 0.35 \\
\hline Peripheral arterial disease (\%) & 37.8 & 45.0 & $75.0^{\mathrm{e}}$ & 0.002 \\
\hline Coronary heart disease $(\%)$ & 34.3 & 34.5 & 53.8 & 0.14 \\
\hline Cerebrovascular disease (\%) & 16.0 & $36.2^{\mathrm{e}}$ & $42.3^{\mathrm{e}}$ & 0.001 \\
\hline Depression symptoms (\%) & 11.3 & 15.5 & 17.4 & 0.53 \\
\hline ApoE $\varepsilon 4(\%)$ & 17.1 & 20.3 & 26.9 & 0.45 \\
\hline
\end{tabular}

Values are means \pm SD

${ }^{a}$ Values are medians with IQR

${ }^{\mathrm{b}}$ Values are geometric means with ranges

${ }^{\mathrm{c}} p$ value for tests of multiple comparisons; ${ }^{\mathrm{d}} p<0.05,{ }^{\mathrm{e}} p<0.01$ vs normal in two-sample comparisons (no adjustment for multiple tests)

time of cognitive assessment. Compared with normal participants, patients with dementia were significantly older, had a longer duration of diabetes, and were more likely to have been hospitalised with hypoglycaemia, less likely to take lipid-lowering medication and more likely to have PAD and CVD. Participants with cognitive impairment without dementia were significantly more likely to have been hospitalised with hypoglycaemia and to have CVD. Important non-significant results included education, depression, ApoE status, $\mathrm{HbA}_{1 \mathrm{c}}$ levels, $\mathrm{BP}$, lipid concentrations and CHD. Additional non-significant variables included waist circumference, prior or current antidepressant use, a history of head injury and a family history of dementia (data not presented).
Multiple logistic regression was used to investigate independent associations with cognitive impairment. Four models were explored in which cognitively normal participants $(n=214)$ were compared with each of the following categories: (1) all cognitively impaired participants grouped as a single variable; (2) cognitive impairment without dementia alone with demented participants excluded; (3) all demented participants; and (4) participants with probable AD alone (Table 2). Dementia was independently associated with older age, male sex, diabetes duration and PAD. Probable AD was associated with the same variables with the exception of PAD. Cognitive impairment without dementia was associated with male sex and CVD. 
Table 2 Independent cross-sectional associations (odds ratios and 95\% CI) comparing non-impaired participants ( $n=214)$ with all cognitive impairment, cognitive impairment without dementia alone, all dementia alone and probable Alzheimer's disease alone

\begin{tabular}{|c|c|c|c|c|}
\hline & $\begin{array}{l}\text { All cognitive impairment } \\
(n=88)\end{array}$ & $\begin{array}{l}\text { Cognitive impairment } \\
(n=60)\end{array}$ & $\begin{array}{l}\text { All dementia } \\
(n=28)\end{array}$ & $\begin{array}{l}\text { Alzheimer's disease } \\
(n=16)\end{array}$ \\
\hline Age (per decade) & & & $5.38(1.73-16.72)^{\mathrm{b}}$ & $11.11(2.60-47.51)^{\mathrm{b}}$ \\
\hline Male sex & $2.68(1.45-4.95)^{\mathrm{b}}$ & $2.40(1.24-4.67)^{\mathrm{b}}$ & $5.25(1.58-17.42)^{\mathrm{b}}$ & $3.92(1.02-15.11)^{\mathrm{a}}$ \\
\hline Duration diabetes (increase of 5 years) & $1.31(1.06-1.63)^{\mathrm{a}}$ & & $1.45(1.03-2.05)^{\mathrm{a}}$ & $1.50(1.04-2.14)^{\mathrm{a}}$ \\
\hline Stroke history & $3.18(1.61-6.26)^{\mathrm{c}}$ & $3.33(1.63-6.77)^{\mathrm{c}}$ & & \\
\hline Peripheral arterial disease & $2.03(1.11-3.73)^{\mathrm{a}}$ & & $4.54(1.39-14.78)^{\mathrm{a}}$ & \\
\hline
\end{tabular}

${ }^{\mathrm{a}} p<0.05 ;{ }^{\mathrm{b}} p<0.01 ;{ }^{\mathrm{c}} p<0.001$

Table 3 Baseline predictors of cognitive status determined an average 7.6 years prior to cognitive assessment

\begin{tabular}{|c|c|c|c|c|}
\hline & $\begin{array}{l}\text { Normal } \\
(n=214)\end{array}$ & $\begin{array}{l}\text { Cognitive impairment } \\
(n=60)\end{array}$ & $\begin{array}{l}\text { Dementia } \\
(n=28)\end{array}$ & $p$ value $^{\mathrm{c}}$ \\
\hline Age at baseline (years) & $67.8 \pm 4.5$ & $68.9 \pm 4.7$ & $71.7 \pm 4.8^{\mathrm{e}}$ & 0.001 \\
\hline Duration diabetes (years) ${ }^{\mathrm{a}}$ & $2.8(0.6-8.0)$ & $4.3(1.0-10.0)$ & $8.3(7.0-9.9)$ & 0.06 \\
\hline \multicolumn{5}{|l|}{ Diabetic treatment $(\%)$} \\
\hline Diet & 37.9 & 35.0 & 32.1 & \multirow{3}{*}{0.17} \\
\hline Oral hypoglycaemic agent & 53.7 & 48.3 & 46.4 & \\
\hline Insulin (with or without oral hypoglycaemic agent ) & 8.4 & 16.7 & 21.4 & \\
\hline Fasting glucose $(\mathrm{mmol} / \mathrm{l})^{\mathrm{a}}$ & $8.2(6.9-10.5)$ & $8.3(7.0-9.9)$ & $8.1(6.7-11.4)$ & 0.97 \\
\hline $\mathrm{HbA}_{1 \mathrm{c}}(\%)^{\mathrm{a}}$ & $7.3(6.4-8.6)$ & $7.5(6.2-8.6)$ & $7.8(6.8-9.1)$ & 0.40 \\
\hline Ever experienced hypoglycaemia (\%) & 24.2 & 30.0 & 28.6 & 0.62 \\
\hline BMI $\left(\mathrm{kg} / \mathrm{m}^{2}\right)$ & $28.9 \pm 4.6$ & $29.6 \pm 4.2$ & $27.7 \pm 4.8$ & 0.20 \\
\hline Overweight/obese waist/hip ratio (\%) & 76.2 & 61.7 & 60.7 & 0.034 \\
\hline Systolic BP (mmHg) & $151 \pm 22$ & $154 \pm 22$ & $161 \pm 22$ & 0.09 \\
\hline Diastolic BP (mmHg) & $79 \pm 12$ & $79 \pm 9$ & $81 \pm 12$ & 0.69 \\
\hline Mean arterial pressure $(\mathrm{mmHg})$ & $103 \pm 13$ & $104 \pm 11$ & $108 \pm 13$ & 0.23 \\
\hline BP-lowering medication (\%) & 56.5 & 56.7 & 57.1 & 1.0 \\
\hline Cholesterol (mmol/l) & $5.5 \pm 1.0$ & $5.1 \pm 0.9$ & $5.5 \pm 1.0$ & 0.06 \\
\hline HDL-cholesterol (mmol/l) & $1.08 \pm 0.32$ & $1.06 \pm 0.34$ & $1.12 \pm 0.32$ & 0.68 \\
\hline Triacylglycerol (mmol/l) $)^{\mathrm{b}}$ & $1.9(1.1-3.2)$ & $1.7(1.0-3.0)$ & $1.9(1.3-2.9)$ & 0.62 \\
\hline Lipid-lowering medication (\%) & 15.0 & 15.0 & 7.1 & 0.53 \\
\hline Albumin:creatinine ratio $(\mathrm{mg} / \mathrm{mmol})^{\mathrm{b}}$ & $2.3(0.8-7.2)$ & $1.9(0.6-6.3)$ & $3.6(0.8-16.1)$ & 0.06 \\
\hline Nephropathy $(\%)$ & 34.1 & 31.0 & 50.0 & 0.20 \\
\hline Retinopathy $(\%)$ & 13.3 & 20.3 & 16.0 & 0.40 \\
\hline Peripheral neuropathy $(\%)$ & 26.7 & 29.6 & 35.7 & 0.59 \\
\hline Peripheral arterial disease (\%) & 21.1 & 28.8 & $57.1^{\mathrm{e}}$ & 0.001 \\
\hline Coronary heart disease $(\%)$ & 28.8 & 39.0 & 42.9 & 0.15 \\
\hline Cerebrovascular disease (\%) & 7.0 & 10.0 & $25.0^{\mathrm{e}}$ & 0.008 \\
\hline Depression $(\%)$ & 21.1 & 27.1 & 35.7 & 0.18 \\
\hline Any exercise in past 2 weeks (\%) & 82.2 & 80.0 & $60.7^{\mathrm{d}}$ & 0.028 \\
\hline \multicolumn{5}{|l|}{ Smoking status $(\%)$} \\
\hline Never & 49.5 & 36.7 & 42.9 & \multirow{3}{*}{0.27} \\
\hline Ex- & 41.0 & 53.5 & 39.3 & \\
\hline Current & 9.4 & 10.0 & 17.9 & \\
\hline Alcohol (standard drinks/day) ${ }^{\mathrm{a}}$ & $0.1(0-0.8)$ & $0(0-0.8)$ & $0(0-0.3)$ & 0.23 \\
\hline
\end{tabular}

Values are means \pm SD

${ }^{\text {a }}$ Values are medians with IQR

${ }^{\mathrm{b}}$ Values are geometric means with ranges

${ }^{\mathrm{c}} p$ value for tests of multiple comparisons; ${ }^{\mathrm{d}} p<0.05,{ }^{\mathrm{e}} p<0.01$ vs normal in two-sample comparisons (no adjustment for multiple tests) 
Table 4 Independent longitudinal baseline predictors (odds ratios and 95\% CI) of cognitive diagnoses, comparing cognitively normal participants $(n=214)$ with all cognitive impairment, cognitive impairment without dementia alone, all dementia alone and probable Alzheimer's disease alone

\begin{tabular}{|c|c|c|c|c|}
\hline & $\begin{array}{l}\text { All cognitive impairment } \\
(n=88)\end{array}$ & $\begin{array}{l}\text { Cognitive impairment } \\
(n=60)\end{array}$ & $\begin{array}{l}\text { All dementia } \\
(n=28)\end{array}$ & $\begin{array}{l}\text { Alzheimer's disease } \\
(n=16)\end{array}$ \\
\hline Age (per decade) & $2.22(1.26-3.91)^{\mathrm{b}}$ & & $4.00(1.59-10.10)^{\mathrm{b}}$ & $9.95(3.09-32.07)^{\mathrm{c}}$ \\
\hline Duration diabetes (increase of 5 years) & $1.34(1.11-1.63)^{\mathrm{b}}$ & & $1.69(1.24-2.32)^{\mathrm{b}}$ & $1.64(1.19-2.25)^{\mathrm{b}}$ \\
\hline Peripheral arterial disease & $2.23(1.25-3.99)^{\mathrm{b}}$ & & $5.35(2.08-13.72)^{\mathrm{c}}$ & \\
\hline Waist/hip ratio (overweight/obese) & $0.44(0.25-0.78)^{\mathrm{b}}$ & $0.52(0.28-0.96)^{\mathrm{a}}$ & $0.21(0.07-0.61)^{\mathrm{b}}$ & \\
\hline Cholesterol $(\mathrm{mmol} / \mathrm{l})$ & & $0.71(0.52-0.98)^{\mathrm{a}}$ & & \\
\hline Diastolic BP (increase $5 \mathrm{mmHg}$ ) & & & & $1.32(1.04-1.69)^{\mathrm{a}}$ \\
\hline Recent exercise & & & $0.26(0.09-0.73)^{\mathrm{a}}$ & \\
\hline
\end{tabular}

${ }^{\mathrm{a}} p<0.05 ;{ }^{\mathrm{b}} p<0.01 ;{ }^{\mathrm{c}} p<0.001$

Longitudinal predictors In bivariate analyses of baseline variables (Table 3), subjects who later developed dementia were older, more likely to have PAD and CVD and less likely to exercise. No differences were seen between normal participants and those with cognitive impairment without dementia. In addition, there were no differences between normal participants and each of the cognitive categories in updated mean fasting glucose, $\mathrm{HbA}_{1 \mathrm{c}}$, or systolic, diastolic or mean arterial BP (data not shown).

Multiple logistic regression was employed as described in the preceding section (Table 4). Independent longitudinal predictors of dementia were older age, diabetes duration and PAD, while higher waist/hip ratios and taking exercise were protective. AD was predicted by age, diabetes duration and diastolic BP. Cognitive impairment without dementia was predicted by higher waist/hip ratios and higher cholesterol levels (i.e. these variables were protective).

\section{Discussion}

In the present study, dementia was evident in almost $10 \%$ of the sample, another $20 \%$ fulfilling criteria for cognitive impairment without dementia. Applying standard criteria, probable or possible AD was present in $86 \%$ of participants with dementia and $39 \%$ had a significant cerebrovascular component. These data highlight the high prevalence of cognitive disorders in community-dwelling older people with diabetes.

There were several main findings in relation to risk factors. Both PAD and diabetes duration were independent predictors of dementia in analyses that controlled for a range of potential confounders, including age and previously implicated risk factors, glycaemic control [9, 13], insulin treatment [14, 15] and hypertension [8, 9]. The association between PAD and dementia was strong and participants with PAD had five times the risk of developing dementia.
We carried out the analysis in participants diagnosed with probable $\mathrm{AD}$ in order to explore potential relationships in the absence of CVD, although we acknowledge that the small numbers of cases limits the strength of our conclusions. Diabetes duration was independently associated with $\mathrm{AD}$ after controlling for confounders and PAD dropped from this model. These findings are consistent with one or more unmeasured diabetes-related factors being involved in the pathogenesis of AD in diabetes over and above CVD and its risk factors. Variables likely to be related to diabetes duration that have been considered possible causes of AD include chronic low-level inflammation, which is associated with atherosclerosis in type 2 diabetes [31], advanced glycation end-products [11], and hyperinsulinaemia and/or insulin resistance [10, 12].

PAD assessed by the ankle/brachial index indicates the presence of severe, diffuse atherosclerosis and PAD has an increased prevalence in diabetes [32]. The present results are consistent with PAD acting as a marker for subclinical cerebrovascular disease since there was an association with dementia but not AD. However, the Cardiovascular Health Study found that a low ankle/brachial index predicted both incident dementia and AD [6]. This disparity may be explained by the small numbers of $\mathrm{AD}$ cases limiting statistical power in the present study. Risk factors for PAD in diabetes include hypertension, hyperglycaemia, dyslipidaemia and smoking [23, 33]; hence, atherosclerosis may explain the relationship between cardiovascular risk factors and dementia in diabetes [8,9]. An important clinical implication is the possibility that the risk of dementia can be reduced by intensive risk factor management.

There were several other findings. The lack of association between ApoE $\varepsilon 4$ and cognitive deficits is consistent with recent reports indicating that diabetes may be a more powerful risk factor for $\mathrm{AD}$ in ApoE \&4-negative participants [34, 35]. The association with male sex in the present sample may reflect the importance of vascular factors in diabetes, as vascular dementia is more common in men [36]. The finding that baseline diastolic $\mathrm{BP}$ predicted $\mathrm{AD}$ is consistent with 
other studies of mid-life BP [37]. Similarly, the protective effect of baseline exercise is consistent with previous research $[38,39]$. It is highly unlikely that central obesity and hypercholesterolaemia protect against dementia [40]; the findings of this study in relation to these factors are probably explained by the participants with dementia having already lost body fat when assessed at baseline, as loss of fat stores is known to occur years before the onset of dementia [40].

The risk factor profile for cognitive impairment without dementia differed from that for dementia, and incident CVD was associated with the former but not the latter. Cognitive impairment without dementia, as defined in the present study, is a broad classification [41] with a high prevalence in diabetes [42]. Mild cognitive impairment is a more restrictive category with a high rate of transition to dementia, but it has recently been shown that the subgroup of mild cognitive impairment associated with CVD is less likely to progress to dementia [43]. Follow-up studies will be required to determine whether these patients will progress to dementia.

The present study has strengths and limitations in addition to those discussed above. The main strengths are the representative nature of the FDS and the comprehensive nature of the diagnostic procedure for cognitive impairment, potential risk factors and possible confounders. The major limitations relate to the cohort study design, with its inherent tendency for recruitment and survivor bias. There was considerable attrition from the FDS; this left a study sample that was relatively healthy but resulted in a fairly small sample with relatively few cases of dementia. Because of the healthy nature of the sample, the variables of interest, cognitive impairment and CVD, were likely to be under-represented in the sample. Conclusions from our study, particularly in relation to the participants with $A D$, need to be drawn with a degree of caution because of small numbers. The study was longitudinal but cognition was not assessed at baseline. Thus we cannot exclude the possibility that participants had dementia at recruitment, which limits the predictive value of the prospective models. Finally, we studied a cohort of diabetic participants and the lack of a non-diabetic comparison group limits potential conclusions to diabetic populations.

PAD is a potent, modifiable risk factor, indicating that atherosclerosis, either directly or indirectly, contributes to the risk of dementia in diabetes. The finding that the duration of diabetes is an independent risk factor for dementia and $\mathrm{AD}$ lends support to existing hypotheses that invoke insulin-related factors or the accumulation of advanced glycation end-products in the development of dementia in older diabetic patients.

Acknowledgements The study was funded by grants from the National Health and Medical Research Council of Australia, the
Diabetes Australia Research Trust, the Medical Research Foundation of Fremantle Hospital and the Raine Foundation, University of Western Australia.

Duality of interest The authors declare that there is no duality of interest associated with this manuscript.

\section{References}

1. Cukierman T, Gerstein HC, Williamson JD (2005) Cognitive decline and dementia in diabetes-systematic overview of prospective observational studies. Diabetologia 48:2460-2469

2. Allen KV, Frier BM, Strachan MW (2004) The relationship between type 2 diabetes and cognitive dysfunction: longitudinal studies and their methodological limitations. Eur J Pharmacol 490:169-175

3. Strachan MW, Deary IJ, Ewing FM, Frier BM (1997) Is type 2 diabetes mellitus associated with an increased risk of cognitive dysfunction? A critical review of published studies. Diabetes Care 20:438-445

4. De la Torre JC (2002) Alzheimer disease as a vascular disorder: nosological evidence. Stroke 33:1152-1162

5. Peila R, Rodriguez BL, Launer LJ (2002) Type 2 diabetes, ApoE gene, and the risk for dementia and related pathologies: the Honolulu-Asia Aging Study. Diabetes 51:1256-1262

6. Newman AB, Fitzpatrick AL, Lopez O et al (2005) Dementia and Alzheimer's disease incidence in relationship to cardiovascular disease in the Cardiovascular Health Study cohort. J Am Geriatr Soc 53:1101-1107

7. Van Oijen M, de Jong FJ, Witteman JCM, Hofman A, Koudstaal PJ, Breteler MMB (2007) Atherosclerosis and risk for dementia. Ann Neurol 61:404-410

8. Xu WL, Qiu CX, Wahlin A, Winblad B, Fratiglioni L (2004) Diabetes mellitus and the risk of dementia in the Kungsholmen project: a six year follow-up study. Neurology 63:1181-1186

9. Whitmer RA, Sidney S, Selby J, Clairborne Johnston S, Yaffe K (2005) Midlife cardiovascular risk factors and risk of dementia in late life. Neurology 64:277-281

10. Cole AR, Astell A, Green C, Sutherland C (2007) Molecular connections between dementia and diabetes. Neurosci Biobehav Rev 31:1046-1063.

11. Sato T, Shimogaito N, Wu X, Kikuchi S, Yamagishi S, Takeuchi M (2006) Toxic advanced glycation end products theory in Alzheimer's disease. Am J Alzheimers Dis Other Dement 21:197-208

12. Carro E, Torres-Aleman I (2004) The role of insulin and insulinlike growth factor I in the molecular and cellular mechanisms underlying the pathology of Alzheimer's disease. Eur J Pharmacol 490:127-133

13. Yaffe K, Blackwell T, Kanaya AM, Davidowitz N, Barrett-Connor E, Krueger K (2004) Diabetes, impaired fasting glucose, and development of cognitive impairment in older women. Neurology 63:658-663

14. Ott A, Stolk RP, van Harskamp F, Pols HAP, Hoffman A, Breteler M (1999) Diabetes mellitus and the risk of dementia: the Rotterdam Study. Neurology 53:1937-1942

15. MacKnight C, Rockwood K, Awalt E, McDowell I (2002) Diabetes mellitus and the risk of dementia, Alzheimer's disease and vascular cognitive impairment in the Canadian Study of Health and Aging. Dement Geriatr Cogn Disord 14:77-83

16. Gregg EW, Yaffe K, Cauley JA et al (2000) Is diabetes associated with cognitive impairment and cognitive decline among older women? Arch Intern Med 160:174-180 
17. Bruce DG, Davis WA, Davis TME (2000) Glycemic control in older diabetic patients in the Fremantle Diabetes Study. J Am Geriatr Soc 48:1449-1453

18. Davis TM, Zimmet P, Davis WA, Bruce DG, Fida S, Mackay IR (2000) Autoantibodies to glutamic acid decarboxylase in diabetic patients from a multi-ethnic Australian community: the Fremantle Diabetes Study. Diabetic Med 17:667-674

19. Bruce DG, Casey G, Davis WA et al (2006) Vascular depression in older people with diabetes. Diabetologia 49:2828-2836

20. Davis TME, Davis W, Mulder JW, Fortune P, Bruce DG (2004) Silent myocardial infarction and its prognosis in a communitybased cohort of diabetic patients: the Fremantle Diabetes Study. Diabetologia 47:395-399

21. Feldman EL, Stevens MJ, Thomas PK, Brown MB, Canal N, Greene DA (1994) A practical two-step quantitative clinical and electrophysiological assessment for the diagnosis and staging of diabetic neuropathy. Diabetes Care 17:1281-1289

22. Davis WA, Knuiman MW, Hendrie D, Davis TME (2005) Determinants of diabetes-attributable non-blood glucose-lowering medication costs for type 2 diabetes: the Fremantle Diabetes Study. Diabetes Care 28:329-336

23. Norman PE, Davis WA, Bruce DG, Davis TM (2006) Peripheral arterial disease and risk of cardiac death in type 2 diabetes. Diabetes Care 29:575-580

24. Bruce DG, Starkstein SE, Davis WA, Davis TME (2005) A prospective study of depression and mortality in patients with type 2 diabetes: the Fremantle Diabetes Study. Diabetologia 48:2532-2539

25. Folstein M, Folstein S, McHugh PR (1975) Mini-mental State: a practical method for grading the cognitive state of patients for the clinician. J Psychiatr Res 12:189-198

26. Jorm AF (1994) A short form of the Informant Questionnaire on Cognitive Decline in the Elderly (IQCODE): development and cross-validation. Psychol Med 24:145-153

27. Morris JC (1993) The clinical dementia rating (CDR): current version and scoring rules. Neurology 43:2412-2414

28. McKhann G, Drachman D, Folstein M, Katzman R, Price D, Stadlan EM (1984) Clinical diagnosis of Alzheimer's disease: report of the NINCDS-ADRDA Work Group. Neurology 34:939-943

29. Roman GC, Tatemichi TK, Erkinjuntti T, Cummings JL, Masdeu JC, Garcia JH (1993) Vascular dementia. Diagnostic criteria for research studies: report of the NINDS-AIREN International Workshop. Neurology 43:250-260

30. McKeith IG, Galasko D, Kosaka K, Perry E.K, Dickson DW, Hansen LA (1996) Consensus guidelines for the clinical and pathologic diagnosis of dementia with Lewy bodies (DLB): report of the Consortium on DLB international workshop. Neurology 47:1113-1124

31. Stehouwer CDA, Gall M, Twisk JWR, Knudsen E, Emeis JJ, Parving H (2002) Increased urinary albumin excretion, endothelial dysfunction, and chronic low-grade inflammation in type 2 diabetes: progressive, interrelated and independently associated with risk of death. Diabetes 51:1157-1165

32. Selvin E, Erlinger T (2004) Prevalence of and risk factors for peripheral arterial disease in the United States. Results from the National Health and Nutrition Examination Survey 1999-2000. Circulation 110:738-743

33. Selvin E, Wattanakit K, Steffes MW, Coresh J, Sharrett AS (2006) $\mathrm{HbA}_{1 \mathrm{c}}$ and peripheral arterial disease in diabetes. Diabetes Care 2:877-882

34. Akomolafe A, Beiser A, Meigs J et al (2006) Diabetes mellitus and risk of developing Alzheimer disease: results from the Framingham Study. Arch Neurol 63:1551-1555, 2006

35. Xu W, Qiu C, Winblad B, Fratiglioni L (2007) The effect of borderline diabetes on the risk of dementia and Alzheimer's disease. Diabetes 56:211-216

36. Jorm AF, Jolley D (1998) The incidence of dementia: a metaanalysis. Neurology 51:728-733

37. Birkenhager WH, Staessen JA (2006) Cognitive function in essential hypertension. Prog Cardiovasc Dis 49:1-10

38. Larson EB, Wang L, Bowen JD et al (2006) Exercise is associated with reduced risk for incident dementia among persons 65 years of age and older. Ann Intern Med 144:73-81

39. Fabrigoule C, Letenneur L, Dartigues JF, Arrouk M, Commenges D, Barberger-Gateau P (1995) Social and leisure activities and risk of dementia: a prospective longitudinal study. J Am Geriatr Soc 43:485-490

40. Gustafson D (2006) Adiposity indices and dementia. Lancet Neurol 5:713-720

41. Tuokko H, Frerichs R, Graham J et al (2003) Five-year follow-up of cognitive impairment with no dementia. Arch Neurol 60: $577-582$

42. Van den Berg E, Kessels RPC, de Haan EHF, Kappele LJ, Biessels GJ (2005) Mild impairments in cognition in patients with type 2 diabetes mellitus: the use of the concepts MCI and CIND. J Neurol Neurosurg Psychiatry 76:1466-1467

43. DeCarli C, Mungas D, Harvey D et al (2004) Memory impairment, but not cerebrovascular disease, predicts progression of MCI to dementia. Neurology 63:220-227 